\title{
Forecast of Tourism Growth in Huangshan City-A Study Based on Grey Model
}

\author{
Cao Wei, Chen Zhen \\ School of Economics, Shanghai University
}

\begin{abstract}
Tourism has become an important pillar industry and an advantageous industry of "rich people and strong cities" in the economy of Huangshan City. This paper applies grey model to respectively calculate the correlation between the comprehensive tourism income of Huangshan City and Huangshan City's regional GDP, financial income, fixed assets investment, per capita net income of farmers, total agriculture output value, total forestry output value, number of visitors throughout the year, and retail sales of social consumer goods. This paper uses the Grey Prediction Model (GM Model) to predict the comprehensive tourism income of Huangshan City. The results show that the comprehensive income of tourism inHuangshan city is highly correlated with the above factors, among which the highest is that the correlation degree of the number of tourist on comprehensive tourism income is 0.8520 . It also predicts Huangshan city tourism comprehensive income in 2020 and in 2050 reached 69.5 billion yuan, 1.6864 trillion yuan respectively.
\end{abstract}

Keywords-Huangshan city; Tourism comprehensive income; Grey system model; Grey prediction model

\section{INTRODUCTION}

Huangshan City is one of the key tourist areas in Anhui Province and in China. By the end of 2016, the city had 97 Grade $\mathrm{A}$ and above tourist attractions, including 8 Grade 5A scenic spots; 48 star hotels, including 27 hotels with 4 or more stars; 167 travel agencies. In 2016, tourists received a total of 51.87 million, an increase of $11.7 \%$ year-on-year, including 2.15 million inbound tourists, an increase of $10.3 \%$ over the previous year, and 49.72 million domestic tourists, an increase of $11.2 \%$; The total tourism revenue of the city for the whole year was 45.01 billion yuan, an increase of $12.3 \%$ year-on-year in 2015, of which foreign exchange revenue from tourism was 670 million US dollars, an increase of 11.3\%; domestic tourism revenue was 40.55 billion yuan, an increase of $11.6 \%[1]$. Rural tourism is a key component of tourism in Huangshan City and occupies an important position in the city's tourism.

Tourism comprehensive income is an important indicator to measure the development trend of tourism. The total tourism revenue in Anhui Province accounts for $13.82 \%$ of the annual GDP of Anhui Province, and the proportion of tourism revenue has risen. Huangshan City's tourism industry contributes more to the GDP of Huangshan City. According to the data, the annual average value of tourism revenue in GDP in Huangshan City is $68.3 \%$, which is increasing year by year,from $63 \%$ in 2009 to $75.48 \%$ in 2015 , the growth rate is as high as $19.8 \%$.

Which factors will affect the income of tourism and how the correlation between them is the main issue of this study.
The existing studies mainly show the following deficiencies: First, the current scholars mainly focus on the collaborative development of agricultural tourism with the local natural endowments, regional culture, etc., and do not give the correlation between various factors [2-4]; the second is that the analysis methods are mainly supported by questionnaire surveys and field surveys [5-6].

Based on the previous research, this paper uses the Grey Relational Analysis method [7-8] to explore the factors affecting tourism income in Huangshan City and measure the correlation of each factor, and apply the grey model to forecast Huangshan City's total tourism revenue in 2020 and 2050. Finally, based on the analysis of empirical results, some suggestions for tourism development in Huangshan City are put forward.

\section{THE ANALYSIS MODEL AND DATA PROCESSING}

\section{A. Gray Relational Analysis method}

The Grey Relational Analysis is a method to measure the degree of relevance between factors and a multi-factor statistical analysis method, which uses gray degree of relevance to describe the strength, size, and order of the relationships among factors. From the perspective of ideas, the relational analysis belongs to the category of geometric processing. The basic idea is to judge whether the connections are close based on the degree of similarity of the sequence curve geometry. That is to say, the closer the geometry is, the closer the development trend is, and the greater the degree of correlation.

Because of the different dimension of data in each factor in the system, in order to ensure the quality and analysis of modeling, the original data must be processed to eliminate the dimension to make it comparable.

Model processing:

In this paper, the analysis of absolute relevance processing is adopted. Because the absolute relevance degree has symmetry, uniqueness and comparability, it can be used to study the correlation analysis of multiple factors.

The setting and initialization of the original sequence

First we set the original number to $x^{(0)}(i)=$ $\left(x^{(0)}(1), x^{(0)}(2), \ldots \ldots, x^{(0)}(n)\right)$

Then, $x^{(0)}(i)$ is initialized processing, that is, each data of the original sequence is divided by the first data of each sequence to obtain $x^{(1)}(i)$ : 


$$
\begin{gathered}
x^{(1)}(i)=\left(\frac{x^{(0)}(1)}{x^{(0)}(1)}, \frac{x^{(0)}(2)}{x^{(0)}(1)}, \ldots \ldots, \frac{x^{(0)}(n)}{x^{(0)}(1)}\right) \\
=\left(x^{(1)}(1), x^{(1)}(2), \ldots \ldots, x^{(1)}(n)\right)
\end{gathered}
$$

The establishment of relevant degree analysis model

After the data is initialized, the degree of correlation between the factors is further analyzed. The mother factor and the child factor need to be determined here. Then the trend curve consistency of the sequence curve geometry of each child factor and the mother factor sequence geometry is compared. be:

Let mother factor $\operatorname{series} x_{0}(i)$ and child factor $\operatorname{series} x_{j}(i)$

$$
\begin{aligned}
& x_{0}(i)=\left(x_{0}(1), x_{0}(2), \ldots \ldots, x_{0}(n)\right) \\
& x_{j}(i)=\left(x_{j}(1), x_{j}(2), \ldots \ldots, x_{j}(n)\right) \\
&(\mathrm{i}=1,2, \ldots \ldots, \mathrm{n} ; \mathrm{j}=1,2, \ldots \ldots, \mathrm{m}) ;
\end{aligned}
$$

Relational coefficient between $x_{0}(i)$ and $x_{j}(i)$ :

$\mathrm{G}_{0 j}(i)$

$=\frac{{ }_{j}^{\min }{ }_{i}^{\text {min }}\left|x_{0}(i)-x_{j}(i)\right|+\mathrm{p}{ }_{j}^{\max }{ }_{i}^{\max }\left|x_{0}(i)-x_{j}(i)\right|}{\left|x_{0}(i)-x_{j}(i)\right|+\mathrm{p}{ }_{j}^{\max }{ }_{i}^{\max }\left|x_{0}(i)-x_{j}(i)\right|}$

Where $\mathrm{G}_{0 j}(i)$ is called the relational coefficient of $x_{0}$ to $x_{j}$ at time $\mathrm{i}$, in the expression of $\mathrm{G}_{0 j}(i)$ :

(2.1) $\left|x_{0}(i)-x_{j}(i)\right|$ is the absolute difference between $x_{0}$ and $x_{j}$ at time $\mathrm{i}$

(2.2)The minimum absolute difference between two levels at each moment is:

$$
\Delta_{\text {min }}={ }_{j}^{\min }{ }_{i}^{\min }\left|x_{0}(i)-x_{j}(i)\right|
$$

(2.3)The maximum absolute difference between two levels at each moment is:

$$
\Delta_{\max }=\max _{i}^{\max }\left|x_{0}(i)-x_{j}(i)\right|
$$

(2.4)The $\mathrm{p}$ in $\mathrm{G}_{0 j}(i)$ is the resolution coefficient, and the effect is to increase the difference between the relational coefficients.

pvalue rule is: Note that $\Delta_{\vartheta}$ is the mean of all the absolute values of the difference:

$\Delta_{\vartheta}=\frac{1}{n * m} \sum_{j=1}^{m} \sum_{i=1}^{n}\left|x_{0}(i)-x_{j}(i)\right|$,

$\varepsilon_{\Delta}=\frac{\Delta_{\vartheta}}{\Delta_{\max }}$, then the value of $\mathrm{p}$ is:

when $\Delta_{\max }>3 \Delta_{\vartheta}, \varepsilon_{\Delta} \leq \mathrm{p} \leq 1.5 \varepsilon_{\Delta} ;$ when $\Delta_{\max } \leq$ $3 \Delta_{\vartheta}, 1.5 \varepsilon_{\Delta} \leq \mathrm{p} \leq 2 \varepsilon_{\Delta}$,

In general, $\mathrm{p}$ takes $(0.1,1)$, usually 0.5 .

The calculation of relevant degree
According to the relational coefficient $\mathrm{G}_{0 j}(i)$ between factors, the relevant degree between each child factor and mother factor is obtained:

$$
\gamma_{0 i}=\frac{1}{N} \sum_{k=1}^{N} \mathrm{G}_{0 j}(k) \quad(\mathrm{i}=1,2,3, \ldots \ldots, \mathrm{n} ; \mathrm{k}=1,
$$

$2,3, \ldots \ldots, \mathrm{n})$

\section{B. Gray Forecast Model}

Gray relevant degree analysis can analyze the correlation between the known child factors and the mother factor in the system, so as to roughly simulate the development trend between the child factor and the mother factor. There is a grey forecasting model in the gray model system. The grey forecasting model is to establish a grey differential forecasting model with a small amount of incomplete information, and makes a long-term description of the ambiguity of the development law of things [10]. Its characteristic is that the use of the gray prediction model does not require a large number of samples, the sample does not need to have a regular distribution, and the accuracy is high.

\section{Model processing:}

The setting of the original sequence and the generation of the accumulated sequence

First we set the original number to $x^{(0)}(t)=$ $\left(x^{(0)}(1), x^{(0)}(2), \ldots \ldots, x^{(0)}(n)\right)$ (where $\mathrm{n}$ is the number of data)

Then initialize the $x^{(0)}(i)$, which is the cumulative generation of the original sequence:

$$
x^{(1)}(t)=\sum_{i=1}^{t} x^{(0)}(i) \quad(\mathrm{t}=1,2,3, \ldots \ldots, \mathrm{n})
$$

$$
\begin{gathered}
\text { Then } \\
\left(x^{(1)}(1), x^{(1)}(2), \ldots \ldots x^{(1)}(n)\right) ;
\end{gathered} \quad x^{(1)}(t), x^{(1)}(t)=
$$

Accumulate the weight coefficient of the generated sequence obeys Yang Hui triangle law, the more accumulated times, the greater the weight of old settlements, so that the number of columns after accumulation is changed according to the monotonous ascending rule of the Yanghui triangle, which plays an essential role in weakening the randomness of the original sequence[12].

Quasi-smooth test and Quasi-exponential test

First, a quasi-smooth check is performed on the original sequence $x^{(0)}(t)$, constructing $\mathrm{p}(\mathrm{t})=\frac{x^{(0)}(k)}{x^{(1)}(k-1)},(\mathrm{k}=2$, $3, \ldots \ldots, \mathrm{n}), \mathrm{p}(\mathrm{t}) \in[0 \varepsilon]$, when $\mathrm{k}$ is greater than 3 , if $\varepsilon<0.5$, then we call $x^{(0)}(t)$ as a quasi-smooth sequence.

Secondly, the exponential test is performed on the accumulated sequence $x^{(1)}(t)$. In order to test whether $x^{(1)}(t)$ has a quasi-exponential law, a formula that can quantitatively describe the degree of coincidence has been introduced: $\sigma(\mathrm{t})=$ $\frac{x^{(1)}(k)}{x^{(1)}(k-1)},(\mathrm{k}=2,3, \ldots \ldots, \mathrm{n}), \sigma(\mathrm{t}) \in[11+\varepsilon]$, when kis greater 3, $\varepsilon<0.5$, then we call $x^{(0)}(t)$ as quasi-exponential law。

When the data passes the quasi-smooth test and the quasi-exponential test, the grey GM $(1,1)$ prediction model can be used for quantitative prediction and calculation. 
Establishment of GM $(1,1)$ Model

Do the adjacent data column processing for $x^{(1)}(t)$ :

$$
Z^{(1)}(t)=\frac{1}{2}\left[x^{(1)}(t)+x^{(1)}(t-1)\right]
$$

Generate $\mathrm{B}$ and constant item vector $\mathrm{Y}$ :

$$
\mathrm{B}=\left[\begin{array}{cc}
-Z^{(1)}(t) & 1 \\
\ldots & \ldots \\
-Z^{(1)}(n+1) & 1
\end{array}\right] \mathrm{Y}=\left[\begin{array}{c}
x^{(0)}(t) \\
\ldots \\
x^{(0)}(n)
\end{array}\right]
$$

Solving Gray Parameter $\hat{a}$ with Least Square Method,then $\hat{a}=[a, u]^{T}=\left(B^{T} B\right)^{-1} B^{T} Y$;

Establish a first-order linear differential equation for $x^{(1)}(t)$ for $x^{(1)}(t), \frac{d x^{(1)}}{d t}+a x^{(1)}=u$, among them, $\mathrm{t}$ is the time parameter, $\mathrm{a}, \mathrm{u}$ is the undetermined coefficient, respectively called the development coefficient and the gray action quantity, the valid interval of $a$ is $(-2,2)$, and the matrix composed of a and $\mathrm{u}$ is $\hat{a}=[a, u]^{T}$.

Substituting the gray parameter $\hat{a}$ into $\frac{d x^{(1)}}{d t}+a x^{(1)}=u$ and solving for $\frac{d x^{(1)}}{d t}+a x^{(1)}=u$ gives the time corresponding function of the model: $x^{(1)}(t+1)=\left[x^{(0)}(1)-\right.$ $\left.\frac{u}{a}\right] e^{-a t}+\frac{u}{a}$, among them, e is a common logarithm. Since $\hat{a}$ is an approximate value obtained by a least-squares method, $\widehat{x^{(1)}}(t+1)$ is an approximate expression.

The calculation of the analog value of the original sequence

The function expressions $\widehat{x^{(1)}}(t+1)$ and $\widehat{x^{(1)}}(t)$ are discretized, and the difference between the two is done in order to restore the original array of $x^{(0)}(i)$ to obtain the approximate data sequence.ie:

$$
\widehat{x^{(0)}}(t+1)=\widehat{x^{(1)}}(t+1)-\widehat{x^{(1)}}(t)
$$

Model error and accuracy test

The error level of the model is mainly reflected by residual $\varepsilon^{(0)}$ and relative error $\Delta$. Its calculation formula is:

$\varepsilon^{(0)}(t)=x^{(0)}(t)-\widehat{x^{(0)}}(t) \quad, \quad \Delta=\left(\Delta_{t}\right)=\left(\mid \varepsilon^{(0)}(\mathrm{t}) /\right.$ $\left.x^{(0)}(\mathrm{t}) \mid\right)(\mathrm{t}=1,2,3, \ldots \ldots, \mathrm{n})$

The test used for model accuracy is the average relative error $\bar{\Delta}$. The formula is:

$$
\bar{\Delta}=\frac{1}{n} \sum_{k=1}^{n} \Delta_{t},(\mathrm{t}=1,2,3, \ldots \ldots, \mathrm{n})
$$

The test standard of model accuracy is: when $\bar{\Delta} \leq 0.10$, the precision reaches one level; when $0.01 \leq \bar{\Delta} \leq 0.05$, the precision reaches two; when $0.05 \leq \bar{\Delta} \leq 0.10$, the precision reaches three; when $0.10 \leq \bar{\Delta} \leq 0.20$, the accuracy reaches four. Levels below 4 do not meet the standard.

\section{Data Sources}

The data used in this paper are from the 2009-2016 annual report of the Huangshan District Government Information Disclosure, in which the per capita disposable income of farmers (yuan) in the Huangshan District government statistics before 2013 is the per capita net income of farmers (yuan) records The statistical yearbook after 2014 uses per capita disposable income (yuan).

\section{EMPIRICAL ANALYSIS RESULTS}

\section{A. Analysis of the Gray Relational Degree of Tourism} Income in Huangshan City

Data Processing and Gray Relational Analysis:

This article adopts 8 factors.

TABLE I CORRELATION ANALYSIS OF TOURISM COMPREHENSIVE INCOME IN HUANGSHAN DISTRICT

\begin{tabular}{lllllllll}
\hline & 2009 & 2010 & 2011 & 2012 & 2013 & 2014 & 2015 & 2016 \\
\hline X0 & 168.15 & 202.1 & 251 & 303 & 314.5 & 354.4 & 400.7 & 450.1 \\
\hline X1 & 266.92 & 309.3 & 378.8 & 424.9 & 470.3 & 507.2 & 530.9 & 576.8 \\
\hline X2 & 31.23 & 44.3 & 64 & 76.9 & 81 & 90.2 & 92.5 & 99 \\
\hline X3 & 341.34 & 454.3 & 370 & 445.2 & 525.1 & 551.7 & 552.5 & 597.7 \\
\hline X4 & 5704 & 6716 & 7952 & 9161 & 10389 & 10942 & 11872 & 12869 \\
\hline X5 & 60.45 & 66.6 & 76.3 & 82 & 89.2 & 91.7 & 95 & 97.12 \\
\hline X6 & 2122.52 & 2544.7 & 3054.4 & 3641.3 & 3732.6 & 4165.1 & 4665.9 & 5187.1 \\
\hline X7 & 107.56 & 126 & 148.3 & 172.1 & 196.1 & 220.3 & 281.1 & 313.1
\end{tabular}

X0: Comprehensive Tourism Revenue; X1: Gross Regional Product; X2: Revenue; X3: Fixed Assets Investment; X4: Per Capita Net Income of Farmers; X5: Total Output Value of Farming Forestry, Forestry, Animal Husbandry and Fishery; X6: Number of Guests Received throughout the Year;
X7: Retail Sales of Consumer Goods. X0 is the mother factor and $\mathrm{X} 1-\mathrm{X} 7$ are the child factors.

First, the results are shown in Table 2: 
TABLE II RESULT DATA AFTER INITIALIZATION

\begin{tabular}{lllllllll}
\hline & 2009 & 2010 & 2011 & 2012 & 2013 & 2014 & 2015 & 2016 \\
\hline $\mathrm{X} 0$ & 1.000 & 1.202 & 1.493 & 1.802 & 1.870 & 2.108 & 2.383 & 2.677 \\
\hline $\mathrm{X} 1$ & 1.000 & 1.159 & 1.419 & 1.592 & 1.762 & 1.900 & 1.989 & 2.161 \\
\hline $\mathrm{X} 2$ & 1.000 & 1.419 & 2.049 & 2.462 & 2.594 & 2.888 & 2.962 & 3.170 \\
\hline $\mathrm{X} 3$ & 1.000 & 1.331 & 1.084 & 1.304 & 1.538 & 1.616 & 1.619 & 1.751 \\
\hline $\mathrm{X} 4$ & 1.000 & 1.177 & 1.394 & 1.606 & 1.821 & 1.918 & 2.081 & 2.256 \\
\hline $\mathrm{X} 5$ & 1.000 & 1.102 & 1.262 & 1.356 & 1.476 & 1.517 & 1.572 & 1.607 \\
\hline $\mathrm{X} 6$ & 1.000 & 1.199 & 1.439 & 1.715 & 1.759 & 1.962 & 2.198 & 2.444 \\
\hline $\mathrm{X} 7$ & 1.000 & 1.171 & 1.379 & 1.600 & 1.823 & 2.048 & 2.613 & 2.911
\end{tabular}

After dimensionless processing, numerical analysis can be performed between the data.

Then find the absolute difference, which is the absolute difference between the mother factor $\mathrm{X} 0$ and other factor factors. The maximum difference is $\Delta_{\max }=1.070$, the minimum difference $\Delta_{\min }=0.000$.

Based on the above results, the results of the rank correlation coefficient (where the resolution coefficientp $=0.5$ ) are obtained as shown in Table 3:

TABLE III CORRELATION COEFFICIENT TABLE

\begin{tabular}{ccccccccc}
\hline & 2009 & 2010 & 2011 & 2012 & 2013 & 2014 & 2015 & 2016 \\
\hline $\mathrm{X} 1$ & 1.000 & 0.926 & 0.878 & 0.718 & 0.832 & 0.720 & 0.576 & 0.509 \\
\hline $\mathrm{X} 2$ & 1.000 & 0.711 & 0.490 & 0.448 & 0.425 & 0.407 & 0.480 & 0.520 \\
\hline $\mathrm{X} 3$ & 1.000 & 0.806 & 0.567 & 0.518 & 0.617 & 0.521 & 0.412 & 0.366 \\
\hline $\mathrm{X} 4$ & 1.000 & 0.955 & 0.844 & 0.732 & 0.916 & 0.738 & 0.639 & 0.560 \\
\hline $\mathrm{X} 5$ & 1.000 & 0.843 & 0.698 & 0.545 & 0.576 & 0.475 & 0.397 & 0.333 \\
\hline X6 & 1.000 & 0.994 & 0.908 & 0.860 & 0.828 & 0.786 & 0.743 & 0.697 \\
\hline X7 & 1.000 & 0.945 & 0.824 & 0.726 & 0.919 & 0.899 & 0.699 & 0.696
\end{tabular}

Finally, the relevant degree between each child factor and the mother factor is obtained, as shown in Table 4:

TABLE IV COMPREHENSIVE TOURISM INCOME CORRELATIONDEGREE IN HUANGSHAN DISTRICT

\begin{tabular}{lllllll}
\hline $\boldsymbol{\gamma}(0,1)$ & $\boldsymbol{\gamma}(0,2)$ & $\boldsymbol{\gamma}(0,3)$ & $\boldsymbol{\gamma}(0,4)$ & $\boldsymbol{\gamma}(0,5)$ & $\boldsymbol{\gamma}(0,6)$ & $\boldsymbol{\gamma}(0,7)$ \\
\hline 0.7699 & 0.5602 & 0.6008 & 0.7980 & 0.6085 & 0.8520 & 0.8386
\end{tabular}

By sorting the relevance degree, you can get:

$\gamma(0,6)>\gamma(0,7)>\gamma(0,4)>\gamma(0,1)>\gamma(0,5)>\gamma(0,3)>\gamma(0,2)$

From the above table and the ranking of relevance, it can be seen that the highest is the correlation of 0.8520 for the total number of visitors received for tourism in the year, followed by the correlation between the retail sales of social consumer goods and the total income for tourism is 0.8386 . In addition, the per capita net income of farmers is 0.7980 for tourism comprehensive income, and the regional GDP, the total output value of agriculture, forestry, animal husbandry and fishery, investment in fixed assets, and fiscal revenue for tourism comprehensive income are: $0.7699,0.6085,0.6008,0.5602$.

2. Huangshan Tourism Revenue Forecast: Grey Prediction Model (GM Model)
Data Processing and Grey Prediction Analysis:

This article is to predict and analyze the total tourism income of Huangshan City. The data adopts the tourism comprehensive income of Huangshan City during the period of 2009-2016 to carry out digital-analog simulation.

$x^{(0)}=\left(\begin{array}{llllll}168.15 & 202.1251303 & 314.5 & 354.4 & 400.7 & 450.1\end{array}\right)$

First, the raw data array is accumulated and represented as a sequence of columns $x^{(1)}$.

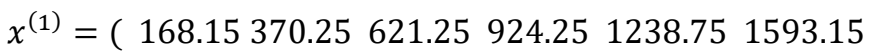

1993.852443 .95 ) 
A quasi-smoothing test is performed on the original $\operatorname{series} x^{(0)}$, and the original series can satisfy the quasi-smooth sequence when $\mathrm{t}=4$. As shown in Table 5:

TABLE V QUASI-SMOOTHNESS TEST

\begin{tabular}{cccccc}
\hline $\mathrm{t}$ & 4 & 5 & 6 & 7 & 8 \\
\hline $\mathrm{P}(\mathrm{t})$ & 0.48772 & 0.34027 & 0.28609 & 0.25151 & 0.22574
\end{tabular}

A quasi-exponential test is performed on the accumulated series $x^{(1)}$, and the accumulated series can be obtained as $\mathrm{t}=4$ to satisfy the quasi-smooth sequence. As shown in Table 6:

TABLE VI QUASI-EXPONENTIAL TEST

\begin{tabular}{cccccc}
\hline $\mathrm{t}$ & 4 & 5 & 6 & 7 & 8 \\
\hline $\boldsymbol{\sigma}(\boldsymbol{t})$ & 1.48773 & 1.34028 & 1.2861 & 1.25151 & 1.22574 \\
\hline
\end{tabular}

Do the adjacent data column processing for $x^{(1)}(t)$ :

$$
Z^{(1)}(t)=(772.75 ; 1081.5 ; 1415.95 ; 1793.5 ; 2218.9)
$$

Least squares estimation of parameter $\hat{a}=[a, u]^{T}$ and calculate:

$$
\hat{a}=[a, u]^{T}=(-0.1063,209.7215)^{T}
$$

Bring in coefficients to determine differential equations

$$
\frac{d x^{(1)}}{d t}-0.1063 x^{(1)}=209.7215
$$

Find the solution of the differential equation and get the time response:

$$
\begin{gathered}
x^{(1)}(t+1)=\left[x^{(0)}(1)-\frac{u}{a}\right] e^{-a t}+\frac{u}{a} \\
x^{(1)}(t+1)=2141.07 e^{0.1063 t}-1972.92 \quad(\mathrm{t}=0, \quad 1,
\end{gathered}
$$

According to the time-response formula, the corresponding cumulative forecast of tourism comprehensive income for Huangshan City from 2009 to 2016 can be calculated separately.

$$
\begin{aligned}
& \widehat{x^{(1)}}(t) \\
& =(168.15,408.28,675.35,972.37,1302.70,1670.07 \\
& 2078.66,2533.06)
\end{aligned}
$$

\begin{tabular}{|c|c|c|c|c|c|c|c|c|}
\hline $\mathrm{t}$ & 1 & 2 & 3 & 4 & 5 & 6 & 7 & 8 \\
\hline & 168 & 240 & 267 & 297 & 330 & 367 & 408 & 454 \\
\hline & .15 & .13 & .06 & .02 & .33 & .38 & .58 & .41 \\
\hline
\end{tabular}

From $\widehat{x^{(0)}}(t)=\widehat{x^{(1)}}(t+1)-\widehat{x^{(1)}}(t)$, the predicted values for each year can be calculated separately, as shown in Table 7:

TABLE VII PREDICTED RESULTS

Using MATLAB, the results of the operation (predicted values) are compared and analyzed with the results (actual values) of the present values. The predicted and actual curves are shown. As shown in Figure 1 below:

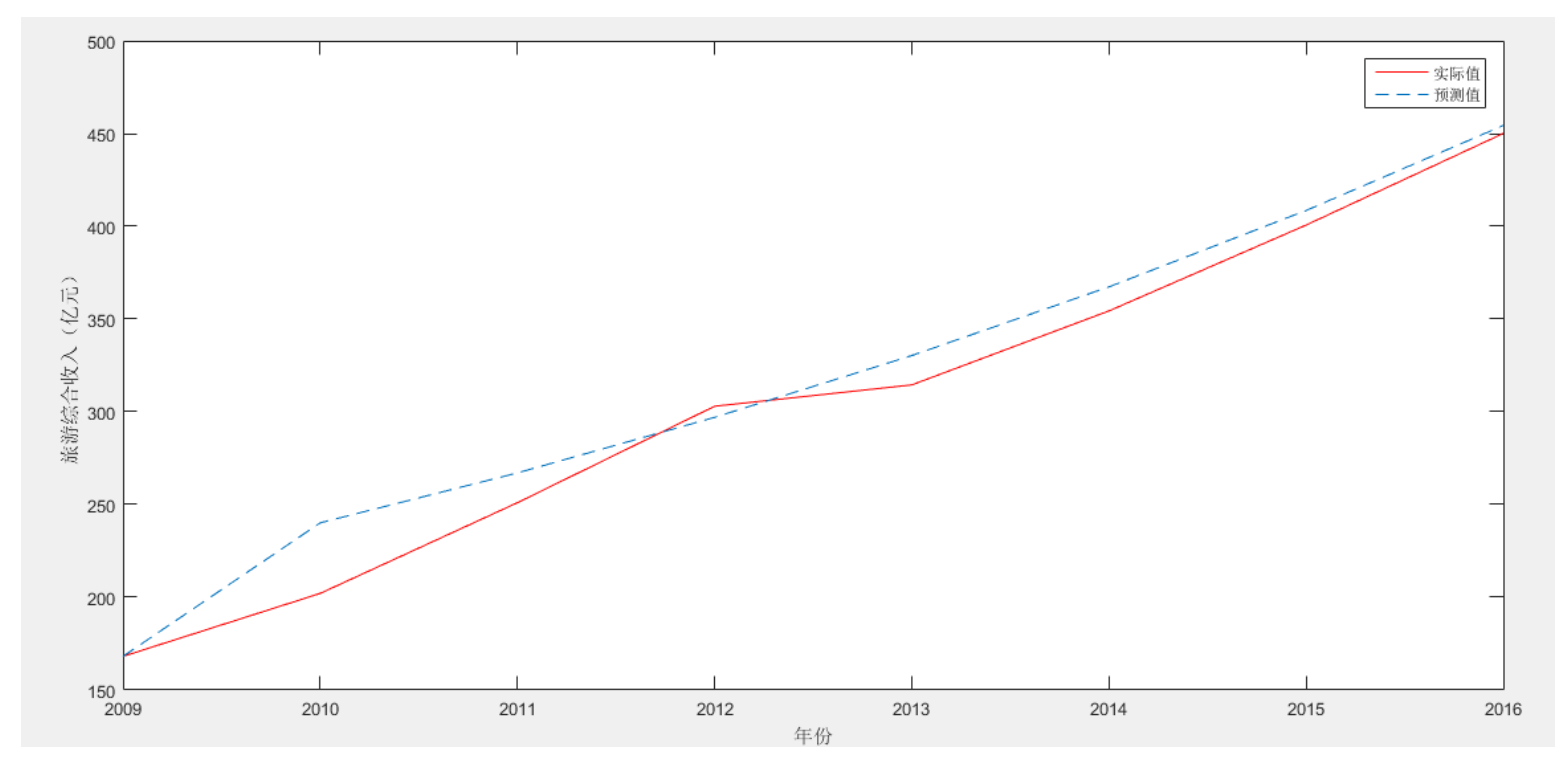

Fig. 1 Trend and value of tourism comprehensive income of Huangshan City from 2009 to 2016

According to Figure 1, the fitting trend of the forecast and actual value of tourism comprehensive income in Huangshan City from 2009 to 2016 is very high. Only in 2010 is there a large deviation between the actual and forecast values. Since 2014, the fitting degree between the forecasting curve and the actual curve has become higher and higher, the trend of the curve has been roughly the same, and the distance value has been continuously decreasing.

In this paper, the relative error test is performed on the above-mentioned data, and the simulated and predicted values of the original data series $x^{(0)}(t)$ are calculated and used as the residual series: 


$$
\varepsilon^{(0)}=(0,-38.0327,-16.0649,5.9823,-15.8299,-12.9782,-7.8816,4.3063)
$$

Relative error $\Delta=\left(\Delta_{t}\right)=\left(\left|\varepsilon^{(0)}(\mathrm{t}) / x^{(0)}(\mathrm{t})\right|\right)$, as shown in the following table:

TABLE VIII RELATIVE ERROR TABLES

\begin{tabular}{|c|c|c|c|c|c|c|c|c|}
\hline$x^{(0)}(\mathrm{t})$ & $\boldsymbol{x}^{(\mathbf{0})}(\mathbf{1})$ & $\boldsymbol{x}^{(\mathbf{0})}(\mathbf{2})$ & $\boldsymbol{x}^{(\mathbf{0})}(\mathbf{3})$ & $\boldsymbol{x}^{(\mathbf{0})}(\mathbf{4})$ & $\boldsymbol{x}^{(\mathbf{0})}(\mathbf{5})$ & $\boldsymbol{x}^{(\mathbf{0})}(\mathbf{6})$ & $\boldsymbol{x}^{(\mathbf{0})}(\mathbf{7})$ & $\boldsymbol{x}^{(\mathbf{0})}(\mathbf{8})$ \\
\hline$\Delta_{t}$ & 0 & 0.1882 & 0.0640 & 0.0197 & 0.0503 & 0.0366 & 0.0197 & 0.0096 \\
\hline
\end{tabular}

The average error is $\bar{\Delta}=\frac{1}{8} \sum_{k=1}^{8} \Delta_{t}=0.048<0.05$ and the accuracy is level 2. Explain that the predictive model is predictive.

According to the established model, the tourism comprehensive income of Huangshan City in 2020 and 2050 is predicted and analyzed respectively. After the grey GM $(1,1)$ forecast model, the forecast results of corresponding years can be obtained respectively.

TABLE IX FORECAST (100 MILLION YUAN)

\begin{tabular}{lll}
\hline Year & 2020 & 2050 \\
\hline Forecast & 695.19 & 16868.31 \\
\hline
\end{tabular}

\section{CONCLUSION}

Results show that the Huangshan city tourism comprehensive income and the correlation between the above factors are high, the highest of which is guests will be able to enter the number of tourist comprehensive income correlation degree is 0.8520, predict Huangshan city tourism comprehensive income in 2020 and in 2050 reached 69.5 billion yuan, 1.6864 trillion yuan respectively.

Tourism is an integrated service industry. It often uses tourism comprehensive income to directly judge the development of tourism. From 2009 to 2016, tourism comprehensive income of Huangshan City increased rapidly at an average annual growth rate of $15 \%$, a variety of factors will affect the development of tourism. Based on the empirical results of this paper, tourism comprehensive income has a high degree of correlation with factors such as number of guests received throughout the year, retail sales of consumer goods, and investment in fixed assets. Therefore, this paper proposes several policy suggestions on the results of the study.

Vigorously dig out the connotation of the Hui culture and integrate it with the geographical landscape of Huangshan to attract tourists for a long time. The Huangshan government should increase investment in fixed assets such as transportation and information infrastructure and build a new tourism model of "tourism + transportation" and "tourism + Internet". Strengthen management, improve the supervision system, and improve service quality. The Huangshan government should improve the regulatory system, rectify the chaos in tourism, eliminate potential safety hazards, and create a comfortable, safe, and beautiful tourism environment.

\section{REFERENCES}

[1] Huangshan Bureau of Statistics: "Statistical Statistic of the National Economic and Social Development of 2016 in Huangshan City" [EB/OL]. April 11, 2017. (In Chinese)

[2] Huang Chenglin. STUDY ON VILLAGE TOURISM INHUANGSHAN CITY [J]. Human Geography. February 2003. (In Chinese)

[3] Liu Shuzhen, Li Yougen. SWOT Analysis of Tourism Development in Huangshan City [J]. Value Engineering. 2009. (In Chinese)

[4] Huang Zhenfang, Lu Lin, Su Qin et al. Rural Tourism Development under the Background of New Urbanization: Theoretical Reflections and Breakthroughs in Dilemma [J]. Geographical Research. 2015. (In Chinese)

[5] Liu Hongrui, Huo Xuexi. Analysis of Demand Behavior of Leisure Agriculture for Urban Residents—-Based on the Survey Data of Civil Officials in Beijing [J]. Agricultural Technology \& Economy.2015.(In Chinese)

[6] Deng Hui, Liu Su. Survey and Reflection on Community Participation in Ethnic Village Tourism: A Comparative Study of Two Ethnic Tourism Villages in Wuling Mountain Area[J].Journal of South-Central University for Nationalities (Humanities and Social Sciences).2017. (In Chinese)

[7] Deng Julong. Grey System Theory Course (First Edition) [M]. Wuhan: Huazhong University of Science and Technology Press. 1990.(In Chinese)

[8] Chen Haiyan. Study on Rural Tourism and Rural Economic Development: A Case Study of Shidu Town, Fangshan District, Beijing [D].Hebei Normal University of Science and Technology. June 2015.(In Chinese)

[9] Zhang Zixu. Accumulation of GM Models in Grey Prediction [J]. Journal of Xi'an Petroleum Institute. September 1997.(In Chinese)

[10] Deng Julong. Grey Prediction and Grey Decision (First Edition) [M]. Wuhan: Huazhong University of Science and Technology Press. 2002. (In Chinese) 